\title{
El campo cultural e intelectual desde la perspectiva del MIR-Praxis (1955-1961)*
}

\section{The Cultural and Intellectual Field from the Perspective of MIR-Praxis (1955- 1961)}

JAVIER DÍAZ

\begin{abstract}
Resumen
En este artículo analizaremos la forma en que el campo intelectual y cultural fue visualizado e interpelado por el Movimiento Izquierda Revolucionaria (Praxis). Esto nos permitirá contribuir a reconstruir la concepción de esta organización política fundada por Silvio Frondizi y a poner de relieve los motivos de los cambios que aquella sufrió. Para ello determinaremos cuáles fueron las voces que intervinieron en los textos culturales de la prensa del MIR-P, qué diferencias presentaron, qué tópicos fueron transitados, qué tipo de interpelaciones se dirigió a los intelectuales.
\end{abstract}

\section{Palabras clave}

Izquierda; Praxis; Intelectuales; Arte; Cultura.

\begin{abstract}
In this article we will analyze the way in which the intellectual and cultural field was regarded and addressed by the "Movimiento Izquierda Revolucionaria (Praxis)". This will allow us to rebuild the conception of this political organization founded by Silvio Frondizi and to highlight the reasons for the changes it experienced. For this purpose, we will identify the voices that intervened in the cultural texts of the MIR-P press, the topics that were covered, and the type of questions addressed to intellectuals.
\end{abstract}

\section{Keywords}

Left; Praxis; Intellectuals; Art; Culture.

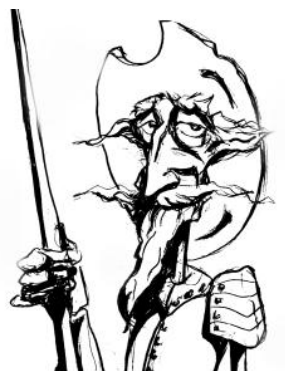

Recibido con pedido de publicación el 2 de marzo de 2021

Aceptado para su publicación el 24 de agosto de 2021

Versión definitiva recibida el 15 de septiembre de 2021

https://doi.org/10.35305/prohistoria.vi36.1526

Javier Díaz, Consejo Nacional de Investigaciones Científicas y Técnicas, Universidad de Buenos Aires, Cergy Paris Université, Centro de Estudios Históricos de los Trabajadores y las Izquierdas, Buenos Aires, Argentina; e-mail: javierdiazbuenosaires@hotmail.com

\footnotetext{
* Agradecemos la atenta lectura y las sugerencias de Ernesto Bohoslavsky y María Elena Fonsalido así como de los evaluadores anónimos de la Revista, que permitieron enriquecer este trabajo.

$(\mathrm{Cc})$ EY-NC-SA

Esta obra se publica bajo licencia Creative Commons. Atribución-NoComercial-CompartirIgual 4.0 Internacional

Díaz, J. El campo cultural e intelectual desde la perspectiva del MIR-Praxis (1955-1961). Prohistoria, Año XXIV, 36, dic. 2021, $1-27$.
} 


\section{Introducción}

En este artículo analizaremos la forma en que el campo intelectual y cultural (no específicamente el argentino) fue visualizado e interpelado por el Movimiento Izquierda Revolucionaria (Praxis). Esto nos permitirá contribuir a reconstruir la cambiante concepción de esta organización política. Nos proponemos determinar qué voces enunciaron los textos culturales de la prensa del MIR-P, qué tópicos fueron transitados, qué tipo de interpelaciones se dirigió a los intelectuales. Nuestra hipótesis es que en el discurso praxista se operó un tenue deslizamiento desde preocupaciones centradas en la libertad artística hacia conceptos próximos a la estética realista y el nacionalismo cultural.

La trayectoria del MIR-P está unida a la de su fundador, Silvio Frondizi (1907-1974), abogado y profesor de historia formado en el pensamiento liberal democrático, quien adoptó desde 1946 el marxismo como método de análisis. Hasta 1955 el grupo Praxis funcionó como un centro de estudio y difusión de ideas. A fines de aquel año vio la luz el periódico de la organización: Revolución. Órgano argentino de esclarecimiento politico, ${ }^{1}$ bajo la dirección de Marcos Kaplan, que coincidió con la publicación en dos tomos (1955 y 1956) de La Realidad Argentina, obra capital de Silvio Frondizi. La tentativa de golpe en junio, el derrocamiento de Juan D. Perón en septiembre y el comienzo de la dictadura militar autodenominada "Revolución Libertadora", con sus consecuencias en términos de deliberación y movilización popular, indudablemente representaron una exigencia de acción.

En las elecciones de 1958, mientras que gran parte de la izquierda llamó a votar por Arturo Frondizi, acompañando las directivas de los organismos dirigentes del peronismo, el MIR-P hizo campaña por el voto en blanco. El giro a derecha del gobierno, la Revolución Cubana y la radicalización de sectores de las vanguardias políticas y la juventud permitieron al MIR-P alcanzar su máximo crecimiento entre 1958 y 1960. A partir de mediados de 1959 el hermano del presidente inició un gradual viraje de tenor "nacional-popular", que desembocó en el folleto Bases y punto de partida para una solución popular (1961). La consecuencia fue la crisis del MIR-P y la escisión de una camada de militantes. El grupo terminó de disolverse en 1964 (Tarcus, 1996: 366-370).

La historiografía ha abordado la vida y el pensamiento de Silvio Frondizi, sin que existan trabajos cuyo objeto de estudio sea el MIR-P. La historia de esta organización ha sido descrita brevemente por Tarcus (1996: 141-149), quien se limitó a enumerar sus publicaciones y sus principales posiciones políticas. En

\footnotetext{
${ }^{1}$ Dos años después el subtítulo pasó a ser Órgano del Movimiento Izquierda Revolucionaria (Praxis).
} 
general no existen investigaciones sobre el itinerario del MIR-P, sus posturas o sus intervenciones en el movimiento social.

Revolución vio la luz entre noviembre de 1955 y mayo de 1960, logrando alcanzar periodicidad mensual y un total de 35 números, y se caracterizó por abordar el conjunto de aspectos de la realidad social, política, económica y cultural. Los autores cuyas plumas aparecían en forma constante eran en su mayoría los principales animadores de la organización: Silvio Frondizi, Marcos Kaplan, Ricardo Napurí, Claudio Perinetti, Alberto Fierro, Néstor Rojo, Ángel Marini, Luis Píriz, Mario Reles y Marisa Costa. Pero el espacio dedicado a las diversas temáticas era jerarquizado de acuerdo a una orientación política. La inmensa mayoría de los artículos puede incluirse en tres rubros: situación político-económica nacional, movimiento obrero e internacionales. Revolución no fue una revista cultural o teórica sino un periódico político: los artículos que analizaremos, en gran parte escritos por colaboradores no pertenecientes al MIR-P, pueden haber distinguido a esta prensa dentro de la izquierda, pero representaron un componente menor y subordinado dentro del discurso praxista. A diferencia del Partido Comunista (PC), y al igual que los también pequeños grupos trotskistas, los praxistas no participaron en las asociaciones de profesionales científicos o artísticos ni publicaron un equivalente a los Cuadernos de Cultura.

Dos aspectos del contexto permitirán comprender mejor la concepción praxista. En las décadas de 1940 y 1950, por un lado, emergió un nuevo modelo intelectual, encarnado principalmente en el "científico social"; la sociología lideró este movimiento de renovación intelectual promovido desde la Comisión Económica para América Latina (CEPAL) (Blanco, 2010). Con el inicio de la guerra fría, por otra parte, el estalinismo occidental emprendió "una condena a las formas y productos culturales identificados con la 'penetración imperialista' y la 'degeneración burguesa', desde la filosofía existencialista hasta el arte abstracto, pasando por la sociología y el psicoanálisis" (Petra, 2013: 215). Los praxistas rechazaron abiertamente el pensamiento cepalino. ${ }^{2}$ A diferencia del estalinismo, sin embargo, fueron receptivos a los aportes de la sociología. Esto puede constatarse fácilmente en los libros de Silvio Frondizi, sobre todo La Realidad Argentina, subtitulado precisamente Ensayo de interpretación sociológica. Se evidencia también en un artículo en el que un destacado militante glosaba La élite del poder de Charles Wright Mills. ${ }^{3}$ Fueron también receptivos del psicoanálisis, contribuyendo a difundir a autores como Erich Fromm, Wilhelm Reich, Abram Kardiner, Karen Horney y, en el ámbito local, a José Bleger; en cambio, y al igual que los partidarios

2 J. A. Campos y M. Reles, "La situación del país a través de la CEPAL", en Revolución núm. 27 (julio de 1959); “Deducciones del informe de la CEPAL", en Revolución núm. 29 (septiembre de 1959).

3 Ángel Marini, “'Capitalismo del pueblo'”, en Revolución núm. 28 (agosto de 1959). 
de Moscú, los militantes y colaboradores del MIR-P expresaron una condena del existencialismo ${ }^{4}$ (Frondizi, 1956b: 13; Frondizi, 1959: XX-XXVIII). Resulta relevante, por lo tanto, prestar atención a los enfoques sobre el campo cultural e intelectual que circularon a través de la prensa praxista como una forma de reconstruir pormenorizadamente el pensamiento del MIR-P. Las referencias al ámbito argentino serán examinadas únicamente como parte del abordaje más general que la organización hizo sobre la cultura y la intelectualidad internacionales de su época.

\section{La obra de Silvio Frondizi como punto de partida (1944-1956)}

Silvio Frondizi formuló su posición respecto de la situación y las tareas de los intelectuales en El Estado Moderno, redactado en una etapa de transición entre el liberalismo democrático y el marxismo. La intelectualidad había tendido a sobrestimar su propio papel y se hallaba dominada por una "desorientación" frente a la realidad contemporánea.

“...¿qué hicieron los intelectuales de Europa y América para defender $[\ldots]$ el patrimonio económico, intelectual y moral de la humanidad o de la mayor parte de ella?, y podemos responder: muy poco [...]. Su delito es, precisamente, el desapego de los problemas vitales del hombre; delito que, en la hora actual, están pagando con creces y que explica, en parte, su confesión de impotencia." (Frondizi, 1944: 14-16)

Lejos de limitarse a constatar esto, el autor entendía que el intelectual "tiene una noble misión que cumplir, ya sea desde los puestos directivos políticos o intelectuales, o desde los más modestos, pero no menos eficientes, de educador de las masas" (Frondizi, 1944: 17). En síntesis, aparecen aquí dos elementos que perdurarán en su concepción posterior: la consideración negativa sobre el papel desempeñado por los intelectuales en general y la postulación de un posible rol positivo para aquellos que comprendieran las raíces de la crisis. Estos últimos, sin embargo, todavía aparecían como quienes deberían desempeñar una función dirigente, la cual posteriormente será atribuida a la clase obrera. En relación con ello, el lugar de enunciación era todavía el del intelectual.

A partir de 1946, ya bajo el signo del marxismo, Silvio Frondizi consideró que, además de la clase obrera y otros sectores explotados, podía contarse con los

\footnotetext{
${ }^{4}$ Néstor Rojo, "Psicoanálisis y ciencia”, en Revolución núm. 23 (marzo de 1959); Ana M. S. de Peisker, “"El segundo sexo' (una crítica)”, en Revolución núm. 4 (mayo de 1956).
} 
"representantes esclarecidos de la intelligentsia". ${ }^{5}$ El estrato intelectual en cuanto tal, concebido como parte de la pequeña burguesía no productiva y parasitaria (Strasser, 1959: 33), no debía entonces ser pensado como parte del sujeto dirigente de la revolución socialista, sino únicamente aquellos "elementos esclarecidos de la intelectualidad que se han puesto al servicio del ascenso proletario" (Frondizi, 1957: 120), entre los cuales obviamente se ubicaba a sí mismo. Se trataba de una minoría, no de la intelectualidad en su conjunto. El contexto argentino reforzaba tales convicciones. Con el triunfo de Perón, en efecto, los intelectuales tendieron a refugiarse en una actitud de defensa corporativa, abandonando la intervención pública. Si por un lado el campo intelectual local se mantuvo dominado por los antiperonistas, por el otro el gobierno sostuvo un discurso antiintelectual (Fiorucci, 2011). Esto explica en parte que Silvio Frondizi concediera "cierto derecho a desconfiar de la posición de los intelectuales frente al régimen de masa, dadas las pruebas de temor demostradas por muchos de ellos" (Frondizi, 1948: 113).

El fundador de Praxis entendía además que su época se caracterizaba entre otras cosas por "el descenso cultural de la sociedad" (Frondizi, 1948: 113) y que el capitalismo había devenido en factor "de oscurantismo cultural" (Frondizi, 1956a: 249). En un folleto postuló que la "crisis espiritual" no era sino una manifestación de la "crisis contemporánea" (Frondizi, 1956b: 5-14). Esta noción totalizante adquirió la función de prisma bajo el cual los praxistas abordaron la cuestión de la cultura. Así, por ejemplo, respecto de la situación nacional el redactor de Revolución afirmaría que "la crisis integral que padece el país toca a todas las actividades culturales y artísticas". ${ }^{6}$ En un plano más general el joven militante Pablo Levín sostuvo que a la burguesía "tener a su servicio los poderes (político, militar, judicial) no le basta para asegurar el dominio económico: necesita controlar todos los aspectos de la cultura, y convertir a ésta en un arma represiva, y en un instrumento de deformación". ${ }^{7}$ La clase capitalista, según él, necesitaba establecer un control riguroso sobre las conciencias, inculcándole al pueblo la ignorancia y la superstición. Por ello los praxistas rechazaban el "pensamiento falsamente progresista que habla de democratizar la cultura en abstracto, pero calla la real imposibilidad de hacerlo sin eliminar el sistema que se opone a ello". 8 Preocupaciones similares pueden leerse en otra nota que advertía que el dominio capitalista en la esfera del consumo buscaba crear en las clases obrera y media

\footnotetext{
${ }_{5}^{5}$ Silvio Frondizi, “La encrucijada argentina”, en Liberación, año I, no 1 (noviembre de 1955), itálicas en el original.

6 Introducción (sin firma) a Edgardo Sierra (colaboración), "Apuntes críticos sobre el cine argentino", en Revolución núm. 10 (diciembre de 1957).

7 Pablo Levín, "Cultura y revolución", en Revolución núm. 5 (agosto de 1956).

${ }^{8}$ Héctor Pedro Requejo, "La experiencia del miedo en la sociedad burguesa. III: Cultura y miedo", en Revolución núm. 34 (abril de 1960).
} 
"una base subjetiva, una personalidad afín a la de la clase dominante"; desde este punto de vista la cancha de fútbol, el hipódromo o el cine eran recursos que permitían a los capitalistas interferir "en la formación afectiva del proletariado", desempeñando la función que antes correspondía a la religión. ${ }^{9}$ En síntesis, la inquietud por la cultura y la subjetividad se inscribía en una noción sobre los aparatos ideológicos que reproducían la hegemonía del capital.

\section{Bajo la "Revolución Libertadora" (1955-1958)}

El conocimiento y abordaje de los problemas de la cultura por parte de Praxis tuvo mucho que ver con las relaciones que entabló Silvio Frondizi con un grupo de artistas y profesionales criados en Europa, cuyas semblanzas biográficas hemos reconstruido como parte de nuestra investigación.

Ana María Sussmann de Peisker (1925-2014) y Peter Sussmann (1927-2019) nacieron en Berlín en el seno de una familia acomodada, con la que llegaron a la Argentina en 1938. Las simpatías políticas de Peter lo llevaron durante su juventud en Buenos Aires a frecuentar el Club Vorwärts. Bajo el primer peronismo trabajó en el diseño gráfico de revistas técnicas. Su hermana se empleó durante los años ‘50 como traductora pública y a fines de esa década comenzaría la carrera de Psicología. Nicolás Rubió (1928) nació en Barcelona en una familia de importantes ingenieros y arquitectos catalanes. Cuando se instalaron en la Argentina, Nicolás rondaba ya los veinte años. Conoció a Peter Sussmann en un taller de pintura del Palacio Barolo. Ambos fundaron el club La Cebolla, en torno al cual solían reunirse jóvenes europeos y argentinos que compartían la oposición al régimen peronista. Entre 1953 y 1954 hicieron juntos un largo viaje por Sudamérica, finalizando en la bienal de São Paulo. Vuelto a la Argentina, Sussmann comenzó a exponer sus trabajos en galerías y salones. A través de Arturo Frondizi conoció a Silvio, quien logró su colaboración con la redacción de algunos textos y la corrección de Revolución, al que le echaba una ojeada antes del envío a imprenta. Roberto Peisker (1924-2008) nació en Buenos Aires pero se crió en Alemania, volviendo a la Argentina con su familia poco antes de la Segunda Guerra Mundial. Se recibió en una escuela técnica y trabajó en estudios de arquitectura. La pareja que formó con Ana María Sussmann tuvo también un vínculo con Silvio Frondizi, en cuya casa de Unquillo pasaron varios veranos durante los años '50. Ella supo traducir para Silvio textos de Marx del alemán y llegó a publicar en Revolución una crítica de El

\footnotetext{
${ }_{9}^{9}$ Roberto Peisker, “La crisis de la vivienda y el sistema capitalista”, en Revolución núm. 3 (febrero de 1956).
} 
Segundo Sexo de Simone de Beauvoir; Roberto hizo lo propio con el tema de la vivienda y la arquitectura. ${ }^{10}$

Si la prensa del MIR-P prestó atención desde su aparición a la cuestión de la cultura, fue en gran medida a través de estas relaciones. En efecto, ya en su primer número vio la luz un artículo en el cual Peter Sussmann rechazaba las posturas que le asignaban al arte una función circunstancial, subordinada. A modo de ejemplo mencionaba no sólo las persecuciones contra los artistas bajo los regímenes fascistas alemán e italiano, sino también la doctrina oficial estalinista: "Esta misma tendencia de direccionismo se observa hoy día en Rusia, donde se indica a los artistas lo que deben y lo que no deben hacer". Pero al mismo tiempo rechazaba la noción del "arte por el arte", a la que vinculaba con una concepción doblemente estrecha: del arte y de la estética. ${ }^{11} \mathrm{El}$ artículo daba cuenta de los postulados que Sussmann defendía:

“Creemos en un arte donde no entran otros componentes que los que son afines al arte mismo. [...] Creemos necesario y beneficioso que el artista siga trabajando con absoluta libertad e independencia, pues sólo de la creación libre podrán cristalizarse los nuevos valores del futuro. [...] Esta es la única posibilidad de mantener el arte en su alto nivel de actividad creadora, cumpliendo así con su función social esencial...". ${ }^{12}$

Sussmann expresaba así una concepción social e histórica del arte, distinguiéndose tanto de una visión instrumental como de una postura esteticista. Meses después, tras el comienzo de la "desestalinización", Sussmann desarrolló una crítica de la política cultural soviética, en particular del "realismo socialista". ${ }^{13}$ En primer lugar, señalaba que se trataba de una doctrina de aparición tardía, es decir, que no había correspondido o acompañado al proceso revolucionario ruso, sino que se remitía al final del Primer Plan Quinquenal bajo Stalin. El autor de la nota hacía suyas las palabras de Lenin, quien había sostenido durante los años 1919-20 que el socialismo debía partir de la cultura y el arte heredados del capitalismo para dar lugar al nacimiento de una "cultura proletaria", concepto que habría sido víctima de una "falsa interpretación" posterior.

\footnotetext{
${ }_{10}$ Entrevistas del autor a Peter Sussmann (28/10/2016) y Nicolás Rubió (7/10/2017); testimonios de Irene Peisker (noviembre de 2016 y diciembre de 2020).

${ }^{11}$ Peter Sussmann, "El arte y su función social”, en Liberación núm. 1 (noviembre de 1955).

12 Peter Sussmann, "El arte y su función social", itálicas en el original.

${ }^{13} \mathrm{El}$ "realismo socialista" fue la doctrina artística impuesta oficialmente en la Unión Soviética por Stalin. Su objetivo proclamado era la exaltación de la clase trabajadora y del régimen comunista.
} 
"Podemos afirmar, por lo tanto, siguiendo el pensamiento de Lenin, que debe educarse al pueblo y elevar su nivel cultural y darle a este un nuevo sentido y forma, y no rebajar el nivel expresivo del arte para hacerlo comprensible inmediatamente al más ignorante con sus [sic] consecuente estancamiento, por falta de impulso creativo y renovador." 14

Como ejemplos de desarrollos artísticos en la Rusia posrevolucionaria, Sussmann consignaba el suprematismo de Kazimir Malevitch -señalando que había contribuido a sentar "las bases del actual arte concreto o no figurativo"-, diversas experiencias en el campo del cubismo y el arte abstracto o los primeros proyectos arquitectónicos cuyas preocupaciones se asemejaban a las de la Bauhaus alemana. ${ }^{15}$ A comienzos de los años ' 30 , en cambio, se había vuelto en la URSS a los conceptos arquitectónicos tradicionales "del estilo burgués del siglo pasado", al mismo tiempo que se establecían proscripciones de artistas, lo que permitía una analogía entre los regímenes estalinista y fascista. Pero además entendía que la doctrina oficial soviética adolecía de limitaciones intrínsecas que aseguraban su necesario agotamiento, lo que ilustraba con el ejemplo de las artes plásticas:

"Al darle tanta importancia al significado anecdótico del cuadro, sin permitir al artista otra forma de expresión, ya sea abstracta o figurativa, el realismo socialista ha señalado sus propias fronteras de expresión y de existencia: la expresión directamente ligada a la exigencia política del momento y cuya existencia caduca en el mismo momento en que cambia esta política." ${ }^{16}$

Al defender la libertad e independencia artísticas y, sobre todo, al reivindicar el legado de Lenin contra el estalinismo, el artículo sintonizaba con el enfoque del Manifiesto por un arte revolucionario independiente, en el cual André Breton y León Trotsky habían recusado el establecimiento de directivas partidarias en materia artística (Breton, Trotsky y Rivera, 1938). El Manifiesto había sido editado en Buenos Aires, poco después de su publicación original en 1938 (Tarcus, 2019: 148). Es probable, por ende, que los praxistas conocieran el contenido de

\footnotetext{
14 Peter Sussmann, “La caída de Stalin y los problemas artísticos", en Revolución núm. 4 (mayo de 1956).

${ }^{15}$ La Bauhaus fue una escuela de arte, arquitectura y diseño fundada en 1919 en la República de Weimar. Nótese el contraste con Spilimbergo (1954: 33), quien un año antes había anatematizado el vanguardismo de los primeros años posteriores a la revolución rusa.

16 Peter Sussmann, "La caída de Stalin y los problemas artísticos", en Revolución núm. 4 (mayo de 1956).
} 
aquel texto, máxime teniendo en cuenta sus numerosos vínculos con las diversas organizaciones trotskistas.

En armonía con Sussmann debe leerse aquella en la que su cuñado Roberto Peisker recurría al Marx de la Crítica a la filosofía del Estado de Hegel para reivindicar la figura de Walter Gropius, primer director de la Bauhaus, y contraponerla a la de Baranov, como representante de la visión arquitectónica de la burocracia soviética. Lo interesante, a nuestro juicio, es que Peisker disputaba al estalinismo el uso adecuado de los conceptos de realismo y de arte socialista.

"En el Bauhaus el arte moderno, y en especial su rama no figurativa 'formalista, decadente y burguesa' según los comunistas, adquiere un sentido social y una función realizadora, se manifiesta como el verdadero arte socialista y realista de nuestro tiempo. [...] el tan mentado 'arte realista socialista', carece de función creadora y realizadora, no concibe sino representa, representando con su pesadez monumental al estado omnipotente (o prepotente) y más aún valores místicos como lo 'glorioso' y lo 'heroico'."17

Creemos útil reponer la trama en la cual se inscribía el pensamiento de Sussmann y Peisker. La defensa del arte no figurativo como auténtica encarnación del realismo y del "arte socialista", en oposición frontal a la doctrina oficial soviética, tenía un precedente muy cercano cronológica y profesionalmente en los artistas nucleados en torno a la Asociación Arte Concreto-Invención. En efecto Tomás Maldonado, quien ya en 1945 había recusado que el arte abstracto fuese reaccionario, como afirmaba Antonio Berni en sintonía con la dirección del PC (Petra, 2013: 314), sostuvo al año siguiente en un artículo que: “El arte concreto será el arte socialista del futuro. [...] El arte concreto es el único arte realista, humanista y revolucionario" (Maldonado, 1997: 50). Como ha demostrado Lucena, las vanguardias rusas (sobre todo el constructivismo y el productivismo) constituían el linaje fundamental que los concretistas elegían para legitimar su propuesta estética, a la cual filosóficamente fundamentaban mediante un acento en los escritos de juventud de Marx (Lucena, 2012: 129-131). Expulsados del PC por su postura estética, Maldonado y Alfredo Hlito fundaron en 1951 la revista Nueva visión, seguida por la editorial homónima, ambas dedicadas a la temática arquitectónica y al diseño gráfico e industrial. Poco antes ambos habían colaborado con Ciclo, revista que incluyó textos del surrealista André Breton y que tenía entre sus directores a Enrique Pichon-Rivière, quien por otra parte llegó a tener una relación estrecha con Silvio Frondizi (Comotto, 1992). En su cuarto número, de

\footnotetext{
17 Roberto Peisker, “Alcance de la arquitectura integral”, en Revolución núm. 5 (agosto de 1956), las itálicas corresponden a negritas en el original.
} 
1953, Nueva visión incluyó un "Homenaje a Gropius". El mismo ejemplar contenía un artículo del crítico de arte brasileño Mário Pedrosa, con quien Maldonado se había vinculado personalmente en Río de Janeiro en 1951 (Grassi, 2018: 139); pocos años antes, Pedrosa había sido el responsable de la traducción al portugués del Manifiesto de Breton y Trotsky (Tarcus, 2019: 150). Hlito, por su parte, fue galardonado en la bienal de São Paulo en 1954 (ocasión en que asistieron Sussmann y Rubió). La visión que Sussmann y Peisker expresaban a mediados de la década de 1950 puede ser mejor comprendida teniendo en cuenta estas coordenadas del ámbito profesional en que actuaban.

En mayo de 1957 vio la luz el único artículo que Nicolás Rubió escribió para Revolución. El joven catalán exponía el modo de funcionamiento del sistema de premiación de los artistas plásticos, en el cual regían los arreglos y favores en función de redes y contactos personales: “Las sociedades apoyarán a los amigos, [...] y allí empieza un mar de fondo de pichuleo, relaciones entrecruzadas al infinito que quitan toda libertad moral e intelectual". ${ }^{18}$ Según esta postura, la pérdida de libertad no era resultado exclusivo del totalitarismo político sino que aparecía como un producto de las leyes del mercado y de la proletarización del trabajo artístico.

La prensa praxista dio cuenta también, a través de la pluma de Mario Reles, de la ruptura del escritor estadounidense Howard Fast con el PC de su país. El joven militante colocaba el episodio dentro de un movimiento más amplio de ruptura con los partidos estalinistas por parte de diversos intelectuales que reaccionaban contra "un ambiente político irrespirable: dogmatismo, burocracia, acatamiento servil a las directivas rusas, aun a aquellas que se refieren a materias propias del artista" ${ }^{19}$ Con esta última indicación Reles parecía también inclinarse hacia el referido Manifiesto de Breton y Trotsky.

\section{Una primera presencia de la "izquierda nacional" (1958)}

La defensa de la libertad artística e intelectual y la crítica del dirigismo cultural estatal informaban un ángulo acorde con la necesidad del MIR-P de diferenciarse de las dos principales estructuras políticas con que competía en la Argentina: el peronismo y el PC. A lo largo de la "Revolución Libertadora", sin embargo, el primero de ellos fue adquiriendo una fisonomía diferente: bajo la represión y la proscripción, el peronismo "viró en la práctica a posiciones nacionalistas revolucionarias y de izquierda, tanto en los comandos clandestinos como en buena

\footnotetext{
${ }^{18}$ Nicolás Rubió, "El salón de 'San Justo' y la posición de los pintores argentinos", en Revolución núm. 7 (mayo de 1957).

${ }^{19}$ Mario Reles, "El caso Howard Fast", en Revolución núm. 11 (febrero de 1958).
} 
parte de las organizaciones sindicales" (Salas, 2015: 17). Dentro del gremialismo comenzó a desarrollarse la llamada "línea dura", referenciada en John W. Cooke, que buscaba continuar la "resistencia" hasta lograr el retorno de Perón (James, 1990: 179-183). En este contexto el PC comenzó a practicar acuerdos con el sindicalismo peronista, concretados en la formación de las 62 Organizaciones (James, 1990: 109-112). A partir del gobierno de Arturo Frondizi iniciado en mayo de 1958, a su vez, las principales organizaciones de izquierda, como el PC y el Partido Socialista Argentino (PSA), así como sectores que abandonaban el radicalismo intransigente (como el que lideraba Ismael Viñas), comenzaron a coincidir con el peronismo en la oposición al desarrollismo y a buscar un acercamiento con él (Tortti, 2009; Pacheco, 2012; Camarero, 2014), siguiendo los pasos antes minoritarios de algunos grupos trotskistas y de aquellos nucleados en torno a Rodolfo Puiggrós o Jorge Abelardo Ramos. Más ampliamente, la misma reorientación se verificó en el movimiento estudiantil universitario (Califa, 2014) y aun en toda la fracción social que encarnó la llamada "nacionalización de las clases medias". La pertenencia de Silvio Frondizi y de gran parte de los praxistas a la universidad los colocaba bajo la fuerte influencia de este movimiento.

En este sentido es interesante detenerse en la recepción temprana que hizo Revolución de un grupo de artistas plásticos vinculados políticamente con Jorge Abelardo Ramos e integrado por Esperilio Bute, Ricardo Carpani, Julia Elena Diz, Mario Mollari y Juan Manuel Sánchez, quienes en 1959 adoptarían el nombre de Movimiento Espartaco. Los praxistas mantuvieron una relación directa con este colectivo: en Revolución fue publicada una entrevista a sus miembros y más tarde un breve comentario de una de sus exposiciones artísticas. ${ }^{20}$ Además Carpani colaboró con un dibujo para la tapa de una edición artesanal que los praxistas hicieron de Reforma o revolución de Rosa Luxemburgo. ${ }^{21}$

En la nota publicada en la prensa del MIR-P, en línea con el discurso de la "izquierda nacional", los motivos típicos del realismo estético se imbricaban con los del nacionalismo cultural. Los artistas argentinos tendían necesariamente, sostenían los futuros espartaquistas, a acomodarse a los gustos de la clase dominante, caracterizada por una mentalidad extranjerizante y un marcado desprecio por todo aquello "genuinamente nacional y por lo tanto popular". Los resultados de esta actitud eran productos vacíos de contenido: "de ninguna manera obras de arte". Como puede verse, la propuesta estética combinaba los tópicos normativos del "realismo socialista" con un discurso nacionalista, según el cual "un arte nacional contribuye a consolidar la conciencia nacional de los pueblos". Estos conceptos vertidos en la entrevista fueron posteriormente, casi con

20 “El arte y la cuestión social”, en Revolución núm. 13 (1 de mayo de 1958).

${ }^{21}$ Entrevistas del autor a Emilio G. (Buenos Aires, 6/09/2017) y Oscar S. (Buenos Aires, 19/11/2018). 
las mismas palabras, el eje del "Manifiesto por un arte revolucionario en América Latina", que el grupo publicó en octubre de 1958 en una revista ligada políticamente a Ramos. ${ }^{22}$

Si bien esta postura tuvo un lugar en la prensa del MIR-P, su enunciación correspondía a una voz externa, de hecho vinculada a un grupo "rival" como el de Ramos. Por eso es significativo que, meses después, Revolución saludara la publicación de aquel manifiesto:

"Desde nuestra integración en las filas revolucionarias hemos venido sosteniendo la imprescindencia [sic] de la cultura [...] respecto de la revolución social latinoamericana. Ante una evidencia tan trascendental como el manifiesto (Revista Política Núm. 2) firmado por Carpani, Mollari, Juan Manuel Sánchez y otros $[\ldots]$, reiteramos nuestra afirmación." 23

Más significativa aún es la recepción del Manifiesto que hizo en la prensa praxista Rafael Farfán (no hemos podido obtener información sobre su identidad). En su primera nota postulaba que había "en gestación una cultura de la Revolución Socialista Latinoamericana", ${ }^{24}$ un año después, se pronunció "por un arte revolucionario que en estos momentos no puede ser otro que un arte de masas" y alabó el Manifiesto del grupo de la "izquierda nacional":

"El manifiesto [...] no ha podido tener mejor escenario que el de Latinoamérica. La amplitud de miras e intención, que abarcan desde una aproximación al enunciado dialéctico, por primera vez en Argentina, hasta la seguridad de una técnica bien definida, permiten apreciar una primera tentativa, que no requiere de otra justificación [...]. Saludamos tal advenimiento con la seguridad de

22 Esperilio Bute, Ricardo Carpani, Julia Elena Diz, Mario Mollari y Juan Manuel Sánchez, "Manifiesto por un arte revolucionario en América Latina", en Política, año I, núm. 2, Buenos Aires, 22 de octubre de 1958. Los mismos artistas, con la excepción de Diz, habían rubricado unos días antes un manifiesto muy similar: "Por un arte nacional", en El Machete, núm. 1 (20/10/1958), Zárate, Provincia de Buenos Aires. El Machete fue editado "por un grupo de jóvenes pertenecientes a Praxis" (Bute Sánchez de Hoyos, 2013: 46, 375 y anexo núm. 6). Los militantes zarateños del MIR-P, que en gran parte provenían del radicalismo intransigente, en general acompañaron el viraje nacional-popular impulsado por Silvio Frondizi desde fines de 1960. Uno de ellos posteriormente ingresó a la agrupación dirigida por Ramos (entrevista del autor a Oscar V.). Sobre el Movimiento Espartaco y su relación con la "izquierda nacional", ver Longoni (2004: 137-142) y Bute Sánchez de Hoyos (2013: 123-309).

23 “Arte Social en Van Riel", en Revolución núm. 19 (noviembre de 1958).

${ }^{24}$ Rafael Farfán (colaboración), "El escritor y la sociedad", en Revolución núm. 10 (diciembre de 1957). 
que nos hallamos ante el planteamiento primario, de cuestiones impostergables...". ${ }^{25}$

Pensamos que en estos textos el llamado a los artistas a cultivar una estética determinada es el hilo que une la identificación de una "cultura de la Revolución Socialista Latinoamericana" en gestación con la alabanza del Manifiesto del grupo ligado a Ramos. En definitiva, desde el periódico del MIR-P se expresó a lo largo de 1958 una valoración en todos los casos positiva de las posturas estéticas de la autodenominada "izquierda nacional", antecedente que debe tenerse en cuenta para explicar el deslizamiento en el discurso cultural que veremos más adelante y, en general, el viraje teórico-político iniciado por Silvio Frondizi desde mediados del año siguiente.

\section{La recepción de Babel (1958-59)}

La colaboración con la prensa del MIR-P de dos figuras oriundas del interior del país permite visualizar una recepción de Babel, la revista publicada en Santiago de Chile por Samuel Glusberg. Luis Franco (1898-1988) fue un poeta y escritor catamarqueño, del pueblo de Belén. A mediados de los años '50 contaba con alrededor de tres décadas de trayectoria literaria, en la que había sabido vincularse a figuras como Lugones, Horacio Quiroga, Martínez Estrada y sobre todo con Glusberg, a través de quien había formado parte del comité editor de Babel en su segunda época. ${ }^{26}$ Compañero de ruta del trotskismo, en Revolución publicó solamente un artículo ${ }^{27}$ y es probable que a través suyo se hubiera efectuado la única colaboración de Martínez Estrada con el periódico praxista. ${ }^{28}$ Más importante fue la participación de Ovidio Omar Amaya (1925-2009), cuya semblanza biográfica hemos reconstruido como parte de nuestra investigación. Nacido y criado en el pueblo rionegrino de San Javier, Amaya creció en una familia de educadores, docentes y directores de escuela. Tras finalizar sus estudios secundarios en el Colegio Nacional de Viedma, se mudó junto a parte de su familia a la Capital Federal. Estudió y se recibió en la Facultad de Derecho de la Universidad de Buenos Aires, lo cual le permitió obtener muy joven un puesto como empleado en la Corte Suprema de la Nación. ${ }^{29}$ Para cuando asumió la presidencia Arturo Frondizi, había ya publicado reseñas de la obra del escritor

\footnotetext{
${ }^{25}$ Rafael Farfán, "Arte y sociedad”, en Revolución núm. 20 (diciembre de 1958).

26 Sobre Franco y su relación con Glusberg ver Tarcus (1996: 118, 210, 260; 2009: 66-69).

${ }^{27}$ Luis Franco, "Epístola a Bernardo Verbitsky, a raíz de sus juicios sobre Sarmiento y Martí", en Revolución núm. 17 (1 de septiembre de 1958).

${ }^{28}$ Ezequiel Martínez Estrada (colaboración), “1810”, en Revolución núm. 4 (mayo de 1956).

${ }^{29}$ Entrevista del autor a Cecilia A. (Buenos Aires, 20/10/2020).
} 
chileno Manuel Rojas (1896-1973) y de El otro Rosas, de Luis Franco. ${ }^{30}$ El verano de 1956 había viajado a Santiago de Chile, donde conoció personalmente a Glusberg y probablemente a Rojas, con quien mantuvo correspondencia. ${ }^{31}$ En 1959 editaría junto con Franco una antología de los Textos Fundamentales de Sarmiento. ${ }^{32}$

La primera colaboración de Amaya fue con un texto sobre el Martín Fierro mediante el cual se incorporaba a una tradición de recuperación política de la obra de José Hernández en el marco de una interpretación económico-clasista de la historia argentina. El rionegrino ilustraba cómo el triunfo del latifundio se hallaba en la base del problema denunciado por el Martín Fierro: la organización nacional había implicado el declive del tasajo y del saladero y la expansión del refinamiento del ganado, lo que significaba la progresiva conversión del suelo en estancias para abastecer al mercado inglés. Amaya hacía un balance de la primera recepción del poema (Avellaneda, Cané, Mitre, Guido, Saldías, Pelliza) para señalar que había sido Lugones, con El Payador, quien "lo bautizó académicamente redimiéndolo de su "pecado original'". Este pecado consistía no sólo en haber inaugurado en Latinoamérica "la literatura de protesta social", lo cual la configuraba como una "obra militante", sino en haber defendido al gaucho mediante una "erguida protesta por el destino de toda una clase social". Pero, anticipando a Lugones, había sido el propio José Hernández quien había intentado redimirse, con la Vuelta, de su pecado original: la Ida. "Indudablemente, la primera parte está escrita por la pluma de un rebelde, la segunda por la de un conforme. En esos siete años, Hernández había progresado en su actuación política, es decir, se había comprometido con los que había que acusar." Esto explicaba que el poeta hubiera votado, como legislador, en favor de la concesión de veinte leguas a Roca como obsequio por haber dirigido la conquista de la Patagonia. Si Martín Fierro representaba la historia del ocaso y desaparición del gaucho, en el fondo de esta cuestión yacía "el problema irresoluto de la posesión de la tierra". ${ }^{33}$

30 Ovidio Omar Amaya, "Manuel Rojas, Hijo de ladrón", en Books Abroad, XXVI (1952), pp. 385-386; Ovidio Omar Amaya, "Manuel Rojas", en El Hogar Argentino, Buenos Aires, 28/9/1956; Ovidio Omar Amaya, "El otro Rosas", en Ciudad, núm. 4-5 (1956), pp. 122-123. En 1940 Rojas y Franco habían firmado, junto a otros intelectuales como Glusberg y Ciro Alegría, una declaración repudiando el asesinato de Trotsky; cf. Babel. Revista de arte y crítica, año XX, vol. II, núm. 15-16, Santiago de Chile, Nascimento, enero-abril de 1941, p. 230. A partir de 1944 Rojas y Franco formaron parte del nuevo equipo editorial de Babel.

31 Carta a Manuel Rojas de Ovidio Omar Amaya, Buenos Aires, 9/10/1956, en Archivo Manuel Rojas, Correspondencia, caja 19, carpeta 319, Centro de Estudios de Literatura Chilena (CELICH), Facultad de Letras, Pontificia Universidad Católica de Chile (UC).

32 Domingo F. Sarmiento, Textos fundamentales. Buenos Aires: Fabril, 1959, 2 tomos. Selección de Luis Franco y Ovidio Omar Amaya.

${ }^{33}$ O.O.A. [Ovidio Omar Amaya], “El Martín Fierro”, en Revolución núm. 15 (1º de julio de 1958). 
Es indudable que, sin citarlo, Amaya estaba glosando el artículo sobre el particular que Samuel Glusberg, bajo el seudónimo de Enrique Espinoza, había publicado once años antes en Babel. En efecto, el editor radicado en Chile había no sólo consignado allí las lecturas que el poema había recibido por parte de las mismas figuras (Avellaneda, Cané, Mitre, Guido, Saldías y Pelliza), sino también formulado muchas de las ideas que en Revolución fueron reproducidas con ligeros cambios, incluida una referencia a El Ombú de Hudson (Espinoza, 1947: 152-156). ${ }^{34}$ En un aspecto Amaya no fue tan lejos como Glusberg, para quien el "sentido social (y hasta socialista)" del poema había implicado, una "insurrección simbólica" cuyo triunfo -literario, suponemos- "es el primero que los campesinos, desengañados de tanto redentor agauchado, sienten como propio" (Espinoza, 1947: 149, 151). Respecto de la Vuelta, el director de Babel había admitido que en ella la preocupación social asomaba "en forma más conciliadora a ratos" (1947: 230): en este sentido, fue más lejos el colaborador de Revolución.

Se trata de una lectura que, en términos generales, participaba de una tradición, fundada desde el PC argentino por Álvaro Yunque (circa 1940-43), de reivindicación del Martín Fierro como antítesis no tanto estética como política del Facundo, aspecto en el cual podía exhibir un paralelismo con exponentes del revisionismo histórico como Ramos (1954: 34-73), Chávez (1956: 67-96) o Hernández Arregui (1957: 154-170). Pero en cuanto a su inscripción historiográfica, cuando señalaba que, en contraposición con la rebeldía de la $I d a$, la filosofía conformista de la Vuelta reflejaba la integración del legislador en la clase dominante, Amaya estaba recuperando al Borges de El tamaño de mi esperanza (1926), que había calificado a la segunda parte del poema de "palinodia desdichadísima" (cit. en Gamerro, 2015: 53), pero sobre todo al Martínez Estrada de Muerte y transfiguración de Martín Fierro (1948), que había hallado en la Vuelta un "clima de concordancia" en el cual se había perdido el "ardor panfletario" de la primera parte (cit. en Ramos, 1954: 49). Esta clave de lectura se oponía frontalmente tanto a Yunque como al revisionismo, en particular a la visión de quienes reivindicaban el roquismo de los últimos años de Hernández (Ramos, 1954: 48-49; Rivera, 1954: 78).

Teniendo esto en cuenta pensamos que la lectura que circuló a través de Revolución, aunque no fue más allá de las nociones historiográficas extendidas en los años cincuenta, en un aspecto sintonizaba con aquella que elaboró Milcíades Peña entre 1955 y 1957, pero que sólo vería la luz pública más de una década después (2014: 298-300). Cuando el joven platense puso de relieve que Hernández, tanto en su poema como en su periódico El Río de la Plata, expresaba los intereses

\footnotetext{
${ }^{34}$ Nótese que Hudson, largamente transitado por Borges, Martínez Estrada, Franco y Glusberg,
} había sido pocos años antes anatematizado por Ramos (1954: 39-41). 
de los estancieros que requerían seguridad para explotar la fuerza de trabajo rural y que disputaban el control estatal con la burguesía comercial porteña, de alguna forma generalizó para el conjunto de la obra las apreciaciones que Amaya (siguiendo a Martínez Estrada) reservaba para la Vuelta. Peña, no obstante, dio un decisivo paso más y dirigió su argumentación a refutar la visión del Martín Fierro como antítesis del Facundo, recusando la idea de una obra que habría expresado la defensa del gaucho. En ese sentido fue mucho más allá y contradijo la lectura de Amaya. Es más que probable, en efecto, teniendo en cuenta los estrechos vínculos que mantenían ambos con Silvio Frondizi y con Luis Franco, que el creador de la revista Fichas haya leído el artículo de Amaya, aunque no sabemos si este mantuvo un diálogo con aquel o conoció sus manuscritos. Por lo demás, lo expuesto muestra que la tesis de Peña sobre el poema polemizaba también con figuras cercanas al reducido espacio trotskista como Glusberg o Amaya. ${ }^{35}$

Tras este texto, una columna sobre "artes y letras" vio la luz en tres números consecutivos de Revolución. Si las iniciales de Amaya únicamente aparecieron firmando la última entrega, dedicada a Manuel Rojas, ${ }^{36}$ es más que probable que las tres sean de su autoría. En particular lo es en el caso de la reseña encomiástica del libro Sarmiento y Martí de Luis Franco. ${ }^{37}$ El autor sostenía en ella que al sanjuanino "se le ha acusado sistemáticamente de anticriollo -digamos- de antinacional", tópico nodal del revisionismo histórico que el libro habría logrado refutar. Al mismo tiempo, la distancia que separaba a Franco tanto de Ricardo Rojas como de Manuel Gálvez le habría permitido al catamarqueño “descolgar el retrato de Sarmiento de la galería de próceres nacionales", en detrimento de estos y no de aquel.

\footnotetext{
35 Un trabajo reciente permite observar la proximidad de ambas lecturas. En efecto, la fertilidad de las apreciaciones de Peña ha sido confirmada por Gamerro: "La Edad de Oro que pinta Hernández es anarquista a medias, sin Estado ni leyes pero con Dios y -sobre todo- con patrón"; por eso las injusticias las cometen "siempre el juez de paz, el comandante de campaña, el almacenero, es decir, los representantes de las instituciones y el comercio burgueses, pero nunca el terrateniente, nunca el patrón. (...) El gaucho canta el sueño (la instrucción) del estanciero: el Estado y sus leyes están de más, mis gauchos y yo nos bastamos solos" (2015: 72). Es con la lectura suscrita por Amaya con la que al mismo tiempo Gamerro parece coincidir: "El movimiento de apropiación de Martín Fierro por parte de la clase dominante comenzó antes de la publicación de la segunda parte y fue encabezado por el propio Hernández, que trató, al escribirla, de obturar o mitigar el potencial libertario de la primera" (2015: 93).

${ }^{36}$ O. A. [Ovidio Omar Amaya], “Artes y letras”, en Revolución no 19 (noviembre de 1958).

37 "Artes y letras", en Revolución núm. 18 (1 de octubre de 1958).
} 


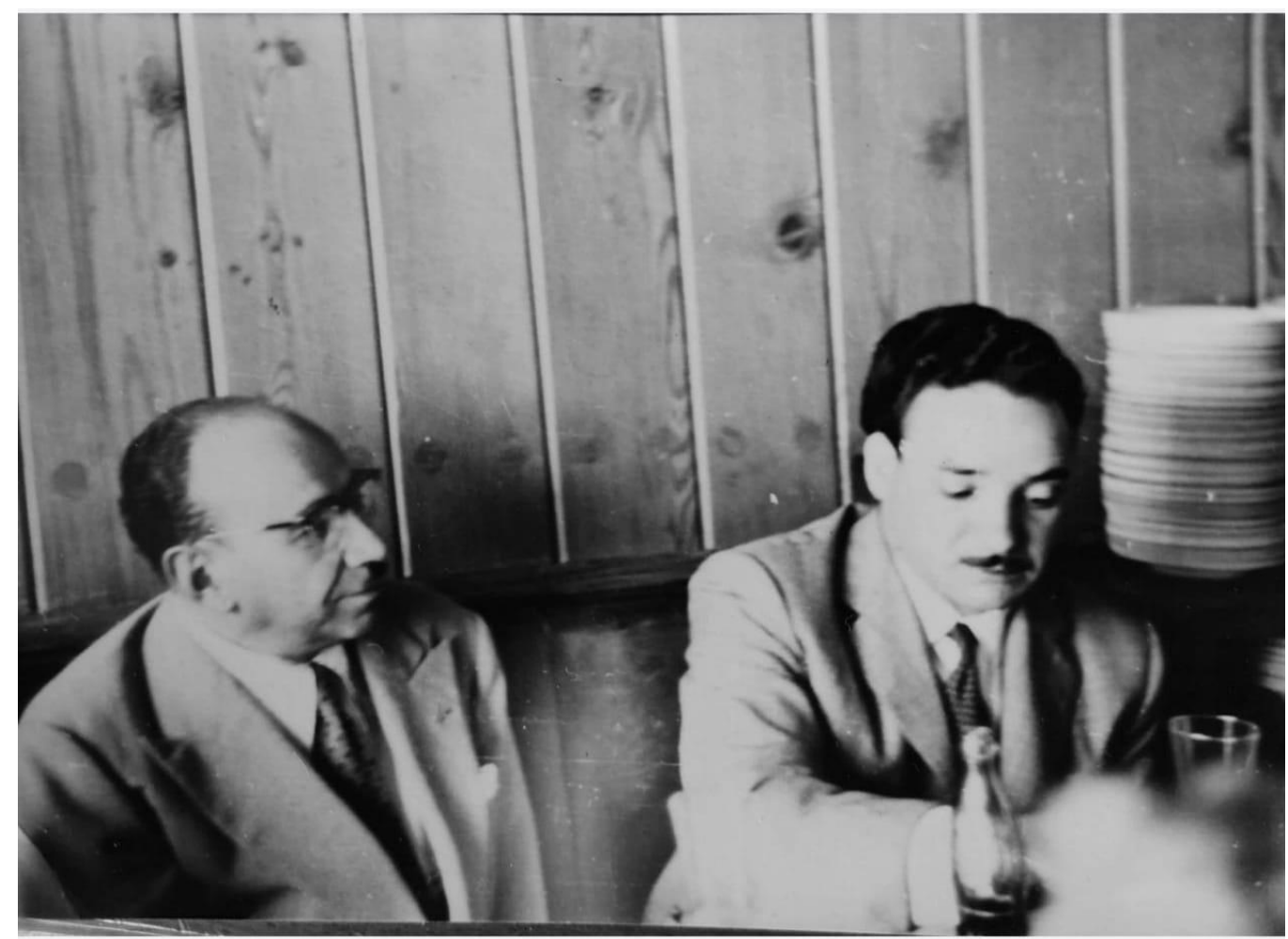

Samuel Glusberg y Ovidio Omar Amaya en Santiago de Chile, enero de 1956 Archivo familia Amaya

En síntesis, se trataba de una clave de lectura que buscaba una delimitación tanto respecto de la historiografía liberal como, quizá más nítidamente, del revisionismo histórico. El trabajo de Franco tenía como objetivo reivindicar conjuntamente, quitándoles el velo bajo el cual los presentaba la interpretación canónica, a las figuras de Sarmiento y Martí, por haber luchado ambos contra rasgos fundamentales de las oligarquías nacionales. El libro de Franco fue producto de una década de trabajo en colaboración con Peña (Tarcus, 2009: 315326), quien por su parte, en los textos de 1955-57 que serían publicados póstumamente, había citado profusamente la obra anterior del catamarqueño a la hora de valorar positivamente al último Sarmiento del período posterior a su presidencia (Peña, 2014: 393-404).

El último texto firmado por Rafael Farfán, en el que ajustaba cuentas con el escritor peruano Ciro Alegría, permite poner de relieve nuevamente las nociones sobre el campo intelectual que atravesaron Revolución. El artículo señalaba que el autor de La serpiente de oro, tras una larga permanencia fuera de su país natal, se había convertido recientemente en colaborador del diario El Comercio de Lima, lo 
cual "significa su entrega a lo más negro de la prensa latinoamericana, destino al parecer de muchos de nuestros intelectuales pequeño-burgueses". Farfán entendía que si Alegría había tenido un rol protagónico en la insurrección de la ciudad peruana de Trujillo en 1932, sus primeras novelas habían sido "el parto intelectual de aquellos días gloriosos". El contenido social de sus obras guardaba entonces estrecha relación con el período ascendente del movimiento aprista, estableciéndose un vínculo de necesidad entre militancia política y contenido artístico. En el mismo sentido sostenía que "la transformación" reciente del novelista implicaba necesariamente su declive intelectual. ${ }^{38}$

El hecho de que el texto contrapusiera la "integración” de Alegría con su pasado "revolucionario" permite indagar el motivo por el cual podía considerarse necesario rechazar la orientación política de un hombre de letras. En efecto, exiliado en Chile durante los años '30, Alegría había sido apadrinado por Glusberg, quien le había dado un lugar en Babel (Alegría, 1976: 188-190). Vista la presencia que la revista chilena tenía en Revolución a través de Amaya y Franco, no es aventurado suponer que los colaboradores de esta prensa buscaran de alguna forma desmarcarse de una figura cuyo prestigio se debía fundamentalmente a las novelas escritas en una época en que había estado asociada a un espacio cercano y ligado al de los praxistas.

\section{Escritores e intelectuales: antecedentes de una reorientación política (1959)}

La cuestión de los escritores también fue abordada por Miguel Prieto, uno de los pocos jóvenes del MIR-P en Bahía Blanca. ${ }^{39}$ En el único artículo que firmó en Revolución, con motivo del viaje a la Argentina de André Malraux (entonces ministro de la flamante V República), Prieto destacó que el prosaico objetivo de la misión, lejos de un propósito cultural, era afirmar el apoyo latinoamericano a la política francesa frente a la lucha de Argelia. Desde su punto de vista el Malraux del presente distaba bastante de aquel que había sido en su juventud "un testigo de la libertad": "Ahora se limita a testimoniar, pero muy involuntariamente, la corrupción de la cultura donde aprendió la admiración por el 'Hombre', así con mayúscula. Pues es invariable el desprecio que los buscadores del Hombre sienten por los hombres concretos."

El autor intentaba demostrar su afirmación argumentando que en las novelas de Malraux los personajes siempre eran solitarios, el Hombre se encontraba en soledad, mientras que las masas y la solidaridad humana cumplían

\footnotetext{
${ }^{38}$ Rafael Farfán, “Ciro Alegría”, en Revolución núm. 21 (enero de 1959).

${ }^{39}$ Entrevistas del autor a Alicia N. (Buenos Aires, 26/2/2018) y Jorge G. (Buenos Aires, 5/4/2018).
} 
la función de una puesta en escena, de un efecto literario; el interés no estaba puesto en las luchas de los pueblos sino en los caracteres excepcionales individuales.

"Los hombres son el pretexto de Malraux, no su motivo. Y cuando el destino de los hombres es una excusa para buscar al Hombre con mayúscula se termina en reaccionario, y es ésta la mejor enseñanza que muy a su pesar nos rinden los intelectuales de la cultura 'cristiano-occidental'. Malraux novelista [...] es un metafísico: rebusca en la soledad de los privilegiados."

Sería difícil no leer en estas palabras los tópicos con que el arte realista se distanciaba del existencialismo. Pero lo que Prieto buscaba poner de relieve era una parábola de naturaleza menos estética o filosófica que sociológica, ya que se trataba "de una constante general de los intelectuales burgueses del siglo XX". El escritor francés simbolizaba a toda una categoría social, dentro de la cual se incluía su versión argentina, cuya recepción del ministro gaullista constituía el verdadero blanco del artículo:

"Y lo que ha venido a hacer aquí André Malraux no es la defensa de la cultura, sino a confirmar en los jóvenes envejecidos por las revistas tipo 'Sur' en la admiración de la Soledad, del Hombre, de la Muerte, del Estilo, de los Gestos, últimos bastiones de la Derecha, en [...] los destinos 'excepcionales' y en su desprecio a los hombres que pugnan por su derecho a la vida de todos los días." 40

El texto tematizaba así la crítica de la élite intelectual liberal encarnada por Borges y Victoria Ocampo, lo cual en este período era un lugar común del discurso de izquierdas (Altamirano, 2013; Terán, 1991).

Un artículo redactado por Héctor Pedro Requejo, asiduo colaborador de Revolución aunque no militante del MIR-P, permite visualizar un deslizamiento en el punto de vista cultural expresado por el periódico entre 1958 y 1959. Se trataba de un texto en el cual su autor pasaba revista, no sin cierta inclinación normativa, a las distintas formas de posicionarse frente al trabajo literario por parte de la intelectualidad. En primer lugar consideraba a los escritores de la ultraderecha argentina, sin dar nombres, a cuyas obras reconocía "cierto grado de nivel estético". En segundo lugar mencionaba sólo al pasar, por considerarlo un tópico largamente transitado, a "los 'peritos de la forma' que padecemos, llámense Borges, Victoria Ocampo, Mujica Láinez". Acto seguido señalaba, aunque

${ }^{40}$ Miguel Prieto, “El caso Malraux”, en Revolución núm. 31 (diciembre de 1959). 
significativamente sin ejemplos nacionales, al escritor comprometido, expresión de la politización de la literatura: Sartre, Gide, de Beauvoir. Se dejaba para el último lugar a los destinatarios del artículo: los "indecisos", a quienes se llamaba a abandonar toda esperanza de hallar un lugar dentro de los "círculos selectos". A partir de esta categorización, Requejo trazaba un cuadro del campo literario argentino:

"Los escritores de nuestro país [...] han optado. [...] Están en la vereda de enfrente del pueblo; éste lo sabe y ellos han aceptado su destino [...]. Objetivamente están en la derecha. Esta identificación es, quizá, su única virtud y también la mejor garantía de su neutralización: las clases populares los conocen y no creen en ellos; sus obras son rechazadas por cuanto no son representativas de fuerzas progresistas [...]. No han encontrado el secreto de lo popular (en el mejor sentido de la palabra), por tanto su[s] obras nacen y mueren dentro de los cenáculos elitoides en que se gestan y difunden. Las palabras que utilizan, en resumen, no tienen otro eco que el de los cuartos vacíos...".

Como puede verse, tras colocar a los escritores de ultraderecha y a los liberales de la revista Sur dentro del campo enfrentado con el pueblo, Requejo negaba toda recepción popular de sus obras literarias, como consecuencia de aquella separación. El autor parecía rechazar todo concepto de vanguardia artística; de hecho, afirmaba que de la crisis y del agravamiento de las contradicciones del capitalismo

“...resulta, en el plano literario, un particular fenómeno de descomposición del cual el surrealismo no fue nada más que una de las tantas muestras agudizadas [...]. Frente a este fenómeno de descomposición que no es nada más que un reflejo de la infraestructura económica, sólo queda tomar partido [...] solidarizándose y confundiéndose con los 'humillados y ofendidos'...". ${ }^{41}$

El realismo como mandato, la pretensión de una identificación unívoca entre contenido del arte y compromiso político, llegaba en este caso al punto de colocar a todo el movimiento surrealista bajo el signo de la descomposición. Las

${ }^{41}$ Héctor Pedro Requejo, "El dilema de los escritores", en Revolución núm. 23 (marzo de 1959). 
inclinaciones del autor parecían así acercarse tanto a la estética vinculada con el ámbito estalinista como a la crítica populista de la élite intelectual liberal. ${ }^{42}$

En sintonía con Requejo puede leerse un texto de Luis Píriz (1937-1976), joven militante destacado y responsable de la célula de la zona norte del Gran Buenos Aires. El agotamiento espiritual de la burguesía, según Píriz, se reflejaba en el plano de la superestructura de forma que la clase dominante era impotente para realizar creaciones de trascendencia social. Retomando un tópico transitado por Sussmann, Píriz colocaba como ejemplo el nuevo vigor que había adquirido la noción de "el arte por el arte". En el siglo XIX, afirmaba siguiendo a G. Plejánov, el arte por el arte estaba en su apogeo, pero nacía como reacción sentimental contra una burguesía en desarrollo.

"Hoy el artista burgués no ataca a su clase moribunda, al contrario, la cuida. No la exalta pues eso sería ditirámbico, risueño, pero ha encontrado una fórmula ideal, salvadora: la abstracción, la introversión, la exaltación de lo formal [...]. El artista burgués se fuga de una realidad social [...], su obra perecedera [...] es negativa, decadente y reaccionaria." 43

En contraposición, el autor ponderaba positivamente al artista revolucionario, para definir al cual tomaba palabras del muralista mexicano Diego Rivera. ${ }^{44}$ Las conclusiones de esta primera nota fueron resumidas con palabras no muy matizadas:

“ $\left.1^{\circ}\right)$ Todas las manifestaciones culturales burguesas están condicionadas a sus intereses de clase y les sirven de aparato propagandístico y moldeador de conciencias.

$2^{\circ}$ ) Existe en marcha una cultura socialista que le sigue en su desarrollo histórico [...].

\footnotetext{
42 No pueden soslayarse los puntos de contacto entre el estalinismo y el nacionalismo argentino. Diez años antes, por ejemplo, Oscar Ivanissevich, ministro de Educación de Perón, había rechazado en discursos públicos a las vanguardias en general y al surrealismo en particular.

${ }_{43}$ Luis J. Píriz, "Cultura y revolución. 1. Hacia manifestaciones culturales revolucionarias", en Revolución núm. 24 (abril de 1959).

${ }^{44}$ La recepción argentina de Diego Rivera tenía un antecedente cercano en la autodenominada "izquierda nacional": las palabras citadas por Píriz, de hecho, parecen haber sido extraídas de Spilimbergo, quien las consideraba ilustrativas del "realismo riveriano" (1954: 24; itálicas en el original). El colaborador de Ramos abogaba en este folleto por "un arte medularmente nacional y popular" (1954: 28). La reivindicación del muralismo había sido heredada de su tío: Lino E. Spilimbergo había sido diez años antes uno de los fundadores del Taller de Arte Mural junto a, entre otros, Antonio Berni y Juan Carlos Castagnino, miembros del PC argentino (Petra, 2013: 312313).
} 
$3^{\circ}$ ) No negamos valor a la producción cultural burguesa de su momento histórico pero analizando sus últimas elaboraciones comprobamos:

a) Un escape de la realidad social, una abstracción al agudo proceso que vive la humanidad.

b) Una primacía de la forma sobre el fondo, que lleva a todas estas actividades a un estancamiento.

Esto hace todas sus obras negativas, vacías, intrascendentes y reaccionarias.

$4^{\circ}$ ) Señalamos a un intelectual como revolucionario [...] cuando la resultante de su obra acompaña a la dinámica social y se adelanta a ella." 45

En el siguiente número Píriz inscribió su conceptualización dentro de la "teoría de la integración mundial" del capitalismo, elaborada por Silvio Frondizi pocos años antes. En el campo de la cultura, sostenía, se estructuraba un "frente cultural integrador" cuyo resultado era la creación en la población de las condiciones psicológicas para la superexplotación. Este frente abarcaba dos concepciones prácticas de la vida. La primera, de origen estadounidense y dirigida a los sectores populares, se caracterizaba por el individualismo, el utilitarismo, la frivolidad, la exaltación de los adelantos técnicos, la glorificación del héroe guerrero, del deportista y del actor. La segunda concepción, proveniente de Europa, estaba dirigida especialmente a los sectores intelectuales, se expresaba en "un existencialismo filosófico-literario negativo y en el revitalizado concepto del arte por el arte" y constituía "la típica expresión de la pequeña burguesía en franca decadencia, indecisa, snobista [sic] y corrompida". ${ }^{46}$ Sin embargo, a pesar de la mayor importancia de aquélla, era la última la que tendía a prender en la intelectualidad argentina. Como conclusión, postulaba el joven militante, los intelectuales revolucionarios tenían frente a este panorama una doble labor: por un lado, la lucha contra los intelectuales burgueses de su país; por el otro, "la inmensa tarea de abrirse hacia las masas", para lo cual el artista o el escritor "tiene una veta inagotable para su inspiración y producción, en los elementos de la realidad nacional". ${ }^{47}$ Podemos identificar en estos pasajes, nuevamente, un punto de contacto con una postura que en la época solían adoptar muchos artistas vinculados al nacionalismo de izquierda o al PC. En efecto, la reactualización de la doctrina del "realismo socialista" efectuada tras la Segunda Guerra Mundial,

\footnotetext{
${ }^{45}$ Luis J. Píriz, "Cultura y revolución. 1. Hacia manifestaciones culturales revolucionarias".

${ }^{46}$ Luis J. Píriz, "Cultura y Revolución. 2. El frente cultural integrador del capitalismo", en Revolución núm. 25 (mayo de 1959).

${ }^{47}$ Luis J. Píriz, “Cultura y Revolución. 2. El frente cultural integrador del capitalismo".
} 
conocida como zhdanovismo, "combinó la condena al formalismo con la exaltación de las tradiciones nacionales" (Petra, 2013: 236). El itinerario conceptual recorrido por Píriz se asemejaba al de Farfán: si el punto de partida era el reconocimiento de la existencia de una "cultura socialista" en desarrollo, el de llegada era un llamado a los intelectuales para adoptar una determinada perspectiva estética.

Los textos de Píriz y Requejo anticipan el replanteo teórico que Silvio Frondizi emprendió desde mediados de 1959. Luis Píriz, que entonces tenía 22 años, al año siguiente fue parte del viraje nacional-popular que signó la última etapa de Praxis.

\section{Conclusión}

Revolución otorgó a los problemas de la cultura un lugar importante, aunque no el central. Un conjunto de preocupaciones fueron constantes a lo largo de toda la trayectoria del MIR-P, tales como la sujeción y deformación de la cultura por parte del capital y la integración ideológica de los intelectuales. Hemos puesto de manifiesto una recepción de conceptos asociados a la Bauhaus alemana y, a lo largo de 1958, de las posturas estéticas de la autodenominada "izquierda nacional". Hemos registrado también la recepción de temáticas, lecturas y nombres asociados a Babel.

El MIR-P dirigió a los intelectuales dos tipos de interpelaciones. Pero si el llamado a expresar en sus obras un compromiso con las clases oprimidas y con el cambio revolucionario puede visualizarse con asiduidad, sólo encontramos una única ocasión en que los convocó a organizarse sindicalmente en su carácter de trabajadores. ${ }^{48}$ En materia cultural, por otra parte, las diferencias en las miradas tenían mucho que ver con la heterogeneidad de los autores. En un sentido general, además, tanto aquellas inspiradas en la Bauhaus como las que se inclinaban por el muralismo de cuño mexicano reivindicaban un concepto realista y compartían la oposición al zhdanovismo.

Pero también puede observarse en el discurso praxista, a través del tiempo, un deslizamiento anterior al replanteo teórico que Silvio Frondizi emprendería desde mediados de 1959 y que desembocaría en la reorientación política de fines de 1960. Durante el período que va desde 1955 hasta 1958 la defensa de la libertad artística ocupó un lugar central, así como la crítica del estalinismo, del "realismo socialista" y sus normativas estéticas. El año en que fue electo Arturo Frondizi puede ser considerado como bisagra: los trabajos de Amaya, radicalmente opuestos a la historiografía revisionista, convivieron con la recepción favorable que

48 "El gremio cinematográfico", en Revolución № 13 (1 de mayo de 1958). 
tuvieron los artistas del futuro Movimiento Espartaco. A lo largo de 1958 y 1959 puede verificarse una silenciosa instilación de nociones asociadas a la estética realista y el nacionalismo cultural, así como una inclinación por delimitarse de la élite intelectual liberal antiperonista. El arte no figurativo constituye un tópico ejemplar, donde puede oírse una disonancia entre la celebración en Sussmann y Peisker y la velada condena en Píriz. La preocupación por la función social del arte fue siendo desplazada por la valoración de la cuestión social en el arte.

Tras la ilegalización de Revolución, en el marco del plan Conintes, Silvio Frondizi impulsó, a partir de fines de 1960, una reorientación política que implicó la adopción de un discurso "nacional-popular". El periódico Movimiento (1961), que expresó la nueva línea, no hizo lugar a temáticas culturales, en lo que quizá podría percibirse como un eco del "antiintelectualismo" que se expandió de la mano de la admiración por el gobierno cubano y del intento de "confluir" con el peronismo (Gilman, 2003).

\section{Referencias bibliográficas}

Alegría, C. (1976). Mucha suerte con harto palo. Memorias. Losada.

Altamirano, C. (2013). Peronismo y cultura de izquierdas [2001]. Siglo XXI.

Blanco, A. (2010). Ciencias sociales en el Cono sur y la génesis de una nueva élite intelectual (1940-1965), en C. Altamirano (ed.), Historia de los intelectuales en América latina. Katz, vol. II.

Breton, A., Trotsky, L. y Rivera, D. (circa 1999). Por un arte revolucionario independiente [1938]. El Viejo Topo.

Bute Sánchez de Hoyos, E. (2013). El Movimiento Espartaco: vanguardia, arte y política, Tesis doctoral. Universidad de Sevilla. [en línea]

\section{https://idus.us.es/handle/11441/31455}

Califa, J. (2014). Reforma y revolución. La radicalización política del movimiento estudiantil de la UBA, 1943-1966. Editorial Universitaria de Buenos Aires.

Camarero, H. (2014). Tras las huellas de una ilusión: el Partido Comunista argentino y sus planteos del Frente Democrático Nacional (1955-1963). Archivos de historia del movimiento obrero y la izquierda (5), 31-50. [en línea] https://doi.org/10.46688/ahmoi.n5.111.

Chávez, F. (1956). Civilización y barbarie en la historia de la cultura argentina. Los Coihues. 
Comotto, A. (1992). El marxismo humanista de Silvio Frondizi, discurso en el homenaje realizado en la Universidad Nacional de La Plata, 16 de septiembre. [en línea] https://elsudamericano.wordpress.com/2012/11/05/aldo-comotto-recuerda-asilvio-frondizi-1992 [última consulta: 29/11/2020].

Espinoza, E. [Samuel Glusberg] (1947). El sentido social de Martín Fierro. Babel. Revista de arte y crítica, Santiago de Chile, X (40), 149-157 y (41), 217-234.

Fiorucci, F. (2011). Intelectuales y peronismo: 1945-1955. Biblos.

Frondizi, S. (1944). El Estado Moderno. Ensayo de crítica constructiva. Roque Depalma, 1960 (3 $3^{\mathrm{a}}$ ed.).

Frondizi, S. (1948). La crisis de la democracia, en S. Frondizi (2014). La integración mundial, última etapa del capitalismo (y otros escritos). Peña Lillo / Continente, selección e introducción de Juan J. Barbero, 105-121.

Frondizi, S. (1956a). La realidad argentina. Ensayo de interpretación sociológica. Tomo II: La revolución socialista. Praxis, 1960 (2ª ed.).

Frondizi, S. (1956b). Fundamento, crisis y porvenir de la democracia. Praxis.

Frondizi, S. (1957). La revolución democrático-burguesa y los países semicoloniales, en S. Frondizi (1958). Doce años de política argentina. Praxis, 119-120.

Frondizi, S. (1959). Interpretación materialista dialéctica de nuestra época [julio], prólogo a S. Frondizi (1960). La realidad argentina. Ensayo de interpretación sociológica. Tomo II: La revolución socialista. Praxis, 2aㅡ ed.

Frondizi, S. (1960). La revolución cubana. Su significación histórica. Ciencias Políticas.

Frondizi, S. (1961). Bases y punto de partida para una solución popular, en S. Frondizi (2014). La integración mundial, última etapa del capitalismo (y otros escritos), op. cit., 149-163.

Gamerro, C. (2015). Facundo o Martín Fierro. Los libros que inventaron la Argentina. Sudamericana.

Gilman, C. (2003). Entre la pluma y el fusil: debates y dilemas del escritor revolucionario en América Latina. Siglo XXI.

Grassi, M. C. (2018). Arte abstracto y psicología de la Gestalt en la Argentina. Una historia de la psicologización del estudio de la forma y el color (1944-1953). Tesis doctoral, Universidad Nacional de $\mathrm{La}$ Plata. [en línea] http://sedici.unlp.edu.ar/handle/10915/77425

Hernández Arregui, J. J. (1957). Imperialismo y cultura. Hachea, 1964 (2ª ed.). 
James, D. (1990). Resistencia e integración. El peronismo y la clase trabajadora argentina, 1946-1976. Sudamericana.

Longoni, A. (2004). Vanguardia y revolución. Ideas y prácticas artístico-políticas en Argentina de los años '60/'70. Tesis doctoral, Universidad de Buenos Aires. [en línea] http://repositorio.filo.uba.ar/handle/filodigital/1865

Lucena, D. (2012). Arte y militancia: encuentros (y desencuentros) entre los artistas y el Partido Comunista Argentino. ArtCultura. Revista de História, Cultura e Arte, 14 (24), 121-133. [en línea]

http://www.seer.ufu.br/index.php/artcultura/article/view/22125

Maldonado, T. (1997). Escritos Preulmianos [1941-1954]. Infinito.

Pacheco, J. (2012). Nacional y popular. El MALENA y la construcción del programa de liberación nacional (1955-1969). Ryr.

Peña, M. (2014). Historia del pueblo argentino [1955-1957]. Emecé, 4ª̣ ed.

Petra, A. (2013). Intelectuales comunistas en la Argentina (1945-1963). Tesis doctoral, Universidad Nacional de La Plata. Disponible en:

http://www.memoria.fahce.unlp.edu.ar/tesis/te.896/te.896.pdf

Ramos, J. A. (1954). Crisis y resurrección de la literatura argentina. Indoamérica.

Rivera, E. (1954). José Hernández y la guerra del Paraguay. Indoamérica.

Salas, E. (2015). Uturuncos. El origen de la guerrilla peronista. Punto de Encuentro, $2^{a}$ ed.

Spilimbergo, J. E. (1954). Diego Rivera y el Arte en la Revolución Mejicana. Indoamérica.

Strasser, C. (coord.) (1959). Las izquierdas en el proceso político argentino. Palestra.

Tarcus, H. (1996). El marxismo olvidado en la Argentina: Silvio Frondizi y Milcíades Peña. El cielo por asalto.

Tarcus, H. (ed.) (2009). Cartas de una hermandad. Leopoldo Lugones, Horacio Quiroga, Ezequiel Martínez Estrada, Luis Franco, Samuel Glusberg. Emecé.

Tarcus, H. (2019). Una voz libertaria en la medianoche del siglo. Nueva Sociedad (283), 138-151.

Terán, O. (1991). Nuestros años sesentas. Puntosur.

Tortti, M. C. (2009). El "viejo" partido socialista y los orígenes de la "nueva" izquierda. Prometeo. 
Yunque, Á. (circa 1940-43). El gauchismo de Martín Fierro. [en línea] https://www.folkloretradiciones.com.ar/folklorecientifico/documentos/EL\%20GAU CHISMO\%20DE\%20MARTIN\%20FIERRO.pdf [última consulta: 2/12/2020]. 